\title{
NON-DESTRUCTIVE EVALUATION OF IN VITRO-STORED PLANTS: A COMPARISON OF VISUAL AND IMAGE ANALYSIS
}

\author{
HAILU M. AYNALEM ${ }^{1}$, TIMOTHY L. RIGHETTI ${ }^{1}$, AND BARBARA M. REED ${ }^{2}$ \\ ${ }^{1}$ Oregon State University, 4017 ALS, Corvallis, OR 97331-7304 \\ ${ }^{2}$ US Department of Agriculture, Agricultural Research Service, National Clonal Germplasm Repository, 33447 Peoria Road, Corvallis,
} OR 97333-2521

(Received 17 January 2006; accepted 31 July 2006; editor M. E. Horn)

\begin{abstract}
Summary
In vitro plants in slow-growth storage require routine evaluation for assessment of viability and need for repropagation. Determination of plantlet health by visual assessment is subjective and varies by genus due to variations in growth pattern and plant structure. Developing a standardized plant evaluation system would improve the efficiency of in vitro storage. This study was initiated to develop digital image analysis techniques for plantlets during slow-growth cold storage and to compare that system with visual examinations. Pear (Pyrus communis L.) cultivars were chosen for this initial trial because they have an open structure and clear internode position for image composition. Pear shoots stored at $4{ }^{\circ} \mathrm{C}$ in tissue culture bags were evaluated monthly by standard visual examination and by digital image analysis. Digital images were evaluated for red, green, blue, modified normalized differences of vegetation index (MNDVI), green/red ratio (G/R), intensity, hue, and saturation at the first two nodes of each plantlet. At 6 mo., the visual ratings had declined steadily for $P$. communis 'Luscious' and 'Bartlett-Swiss', while 'Belle Lucrative' and 'Louise Bonne de Jersey' ratings did not show significant declines until 9 mo. Correlations between visual ratings and G/R and MNDVI values were significant $\left(r^{2} \geq 0.5\right)$ for all cultivars. Regression analysis indicated that the MNDVI and G/R ratios changed significantly over the 15-mo. rating period for most cultivars. Intensity, hue and saturation values were not consistently significant and did not correlate with visual ratings. These results will assist in the development of digital imaging as an alternative technique for evaluation of stored in vitro plantlets.
\end{abstract}

Key words: cold storage; germplasm storage; image analysis; micropropagation; pear.

\section{INTRODUCTION}

The two main strategies of in vitro conservation, slow growth in cold storage for short- and medium-term storage, and cryopreservation in liquid nitrogen for long-term storage, are used as alternative germplasm conservation and exchange methods in many countries throughout the world. The main advantages of in vitro culture conservation are the need for less storage space as well as the maintenance of germplasm in an environment free of pests and pathogens, thereby facilitating easy exchange (Engelmann, 1991; Smith, 1995; Reed et al., 2005). Cold-stored in vitro plants decline over time and it is often difficult to determine their health by visual examination. Visual assessment is not very reproducible; therefore, a more accurate system to detect the decline and death of plants is needed to reduce losses in storage.

The physical condition of explants is very important for successful micropropagation and storage. In vitro-stored plants under slow-growth conditions in heat-sealable gas-permeable polyethylene bags require routine non-destructive evaluation to assess viability and repropagation timing. In vitro plantlets may look unhealthy, but the actual growing points might be viable. Therefore, some plants might appear dead but could be revived and recultured. The currently used procedures to evaluate stored plantlets are:
(1) visual evaluation at fixed intervals; (2) reculture at a fixed interval; and (3) reculture when half of the duplicate set of stored plantlets appears near death.

Visual evaluations at fixed intervals were developed in several laboratories. Reed (1991, 1992, 1993, 2002) developed a visual rating system on a $0-5$ scale for strawberry and blackberry based on the color of leaves, stems and shoot tips, and etiolation. Plants were evaluated at 4-mo. intervals. The International Center for Tropical Agriculture (CIAT) developed descriptors for viability evaluation of in vitro-stored cassava (IPGRI/CIAT, 1994). Evaluations were carried out monthly with data taken on browning, defoliation, and bleaching of the stored plantlets. The degree of defoliation was a better indicator than bleaching for determining culture viability and subculturing time. Wanas et al. (1986) analyzed the survival of the terminal shoots of stored pear plantlets every 6 mo. during a growth limitation study for germplasm conservation. Sarkar and Naik (1998) recorded the percentage of surviving potato shoots and shoot growth after 30 mo. of minimal growth storage on medium with sucrose and mannitol and compared two photoperiods. They used a $0-5$ visual survival evaluation scale by observing the number of green shoots, leaf senescence, viable nodes, and presence or absence of roots. The three factors showed strong interactions in their effects on plant survival. 
Another commonly used procedure is reculturing at a set interval. Ashmore (1997) observed in vitro cassava accessions and found that the appropriate time for subculture of the stored plantlets varied from 8 to $17 \mathrm{mo}$. depending on the genotype response to the standard culture conditions. Four replicates of cultivated and wild coffee relatives maintained in cold storage required subculture after 6-7 mo. (Dussert et al., 1997).

Reculture when half the stored plantlets are near death is also used in germplasm storage. At the International Network for the Improvement of Banana and Plantain (INIBAP) germplasm transit centre in Belgium, all stored cultures are visually inspected each month for viability, necrosis, blackening, bacterial or fungal contamination, and hyperhydricity (Van de Houwe, 1999). The average storage duration was $1 \mathrm{yr}$, and the subculturing interval was between 3 and $22 \mathrm{mo}$. At the National Bureau of Plant Genetic Resources India, the in vitro germplasm is evaluated visually every month. Subcultures occur when one accession is reduced to half of its original numbers due to contamination or necrosis (S. Gupta, New Delhi, 2004, personal communication).

Color change, particularly a loss of greenness, is an important component of the health of in vitro-stored plantlets. Digital image color analysis of in vitro plants has possible advantages for quantifying the health of stored plants. In image analysis, color is used as a parameter for measuring plant health, quality of biological products, and agricultural processes in general (Miller and Delwiche, 1989; Schrevens and Raeymaeckers, 1992; Alchanatis et al., 1993; Sacks and Shaw, 1994; Cliff et al., 2002). Color perception by the human eye is subjective and not reproducible (Neuman et al., 1989; Gunasekaran and Ding, 1994). This is especially true when dealing with different species or making repeated evaluations. A more accurate, objective, and reproducible system to detect the decline of plant health would aid in repropagation decisions and reduce losses of plant cultures in storage. Image color analysis of in vitro plants has practical uses as a non-destructive method for quantifying the health of stored plantlets. It would be desirable to develop effective automated mechanical or robotic methods for determining the health of each in vitro accession in large-scale in vitro plant germplasm collections. An image-analysis technique for quantification of plant health would provide a significant advantage by allowing the health of each plantlet to be accurately determined, allowing timely repropagation.

Digital cameras provide red, green, and blue (RGB) color images with more information than simple grey-level images (Karcher and Richardson, 2003). Digital cameras use visible light in red $(500-700 \mathrm{~nm})$, green $(450-650 \mathrm{~nm})$, and blue $(400-500 \mathrm{~nm})$ spectrums similar to human vision $(350-700 \mathrm{~nm}$; Paulsen and McClure, 1986).

Color ratios are more accurate than hue methods for analysis on color differences of tomato fruit color (Choi et al., 1995). Normalized difference of vegetative index $\{\mathrm{NDVI}=$ [near infrared $(\mathrm{NIR})-\mathrm{red}] /(\mathrm{NIR}+\mathrm{red})\}$ is a common index that provides a standardized method of comparing vegetation greenness in images taken by airplanes and satellites. The red and the near infrared parts of the electromagnetic spectrum are used mostly for vegetative indexes because red wavelengths are more absorbed by the chlorophyll in leafy green vegetation while infrared wavelengths are reflected. A ratio involving red and infrared wavelengths is more sensitive to vegetation differences. In some cases, color ratios of
RGB could be used to grade peaches, and using ratios solved image analysis problems caused by variations in the intensity of illumination (Miller and Delwiche, 1989; Adamsen et al., 1999). Changes in color values or color ratios could serve as indicators of deterioration of stored tissue-cultured plants.

The goals of this project were to test image analysis techniques to evaluate the health of plantlets during slow growth storage and to compare results from a digital image system with that from standard visual evaluations. The image-analysis study used four pear genotypes from the National Clone Germplasm Repository (NCGR) Corvallis in vitro collection. A digital image technique was used to evaluate the health of stored pear plantlets by measuring RGB colors, determining a modified normalized differences of vegetation index (MNDVI) measuring visible light, green-to-red ratio (G/R), and hue, saturation and intensity (HSI) of in vitro plants, and comparing them with standard visual evaluations.

\section{Materials and Methods}

Plant materials. Pear plants were chosen for this initial trial because they have a good structure and clear internode positions for image composition. Four Pyrus communis L. cultivars were selected for study based on responses previously determined through visual assessment: P.I. 263680 'Belle Lucrative' (local identifying number 228.001) and P.I. 541220 'Louise Bonne de Jersey' (358.002) that normally store for $3 \mathrm{yr}$ and P.I. 541322 'Luscious' (367.001) and P.I. 267940 'Bartlett-Swiss compatible with Quince' (1347.001) that normally store only $1 \mathrm{yr}$ (Reed and Chang, 1997).

Culture and storage conditions. Pear shoots were multiplied on $40 \mathrm{ml}$ Cheng's medium (Cheng, 1979) with 2.25 $\mu M \mathrm{~N}^{6}$-benzyladenine (BA), $3.5 \mathrm{~g}$ agar (Difco), and $1.45 \mathrm{~g}$ Gelrite (gellan gum powder, PhytoTechnology Labs) per liter at pH 5.2 (Reed and Chang, 1997). Storage medium was the same but without BA. Medium was dispensed before autoclaving. Cultures were grown in Magenta GA7 boxes (Magenta Corp., Chicago, IL, USA) at $25^{\circ} \mathrm{C}$ under a 16-h light/8-h dark photoperiod with $\left(25 \mu \mathrm{mol} \mathrm{m}{ }^{-2} \mathrm{~s}^{-1}\right)$ photosynthetic photon flux supplied by cool-white fluorescent bulbs. Five plantlets $(2-3 \mathrm{~cm})$ from each accession were transferred to semi-permeable tissue-culture bags with five individual sections $(15 \times 150 \mathrm{~mm})$ and $10 \mathrm{ml}$ medium for storage (Star-Pac, Garner Enterprises, Willis, TX, USA). The plants sealed in bags were grown for $1 \mathrm{wk}$ in the growth room and then for $1 \mathrm{wk}$ under cold acclimatization conditions $\left[22^{\circ} \mathrm{C}\right.$, 8-h light $\left(10 \mu \mathrm{mol} \mathrm{m}{ }^{-2} \mathrm{~s}^{-1}\right)$ and $1^{\circ} \mathrm{C}, 16-\mathrm{h}$ dark] before they were stored under a $12-\mathrm{h}\left(3 \mu \mathrm{mol} \mathrm{m}{ }^{-2} \mathrm{~s}^{-1}\right)$ photoperiod at $4^{\circ} \mathrm{C}$ (Reed et al., 1998; Reed, 2002).

Visual evaluation. The first evaluation was on the first day of cold storage after cold acclimatization and continued monthly for 15 mo. Ratings were assigned on a $0-5$ scale (Reed, 1992). The ratings were: 5 , dark green leaves and stems, no etiolation, and base green; 4, green leaves and stems, but little etiolation; 3, shoot tips, upper leaves, and base green, but with some etiolation present; 2 , shoot tip green, leaves and stems mostly brown, base might be brown (remove for micropropagation); 1, plantlet mostly brown, only extreme shoot tips green, much of base dark brown; 0, all brown, no visible green on shoot tip (Reed, 1999).

Statistical analysis. Mean rating values and standard deviations for each cultivar were determined. The visual evaluation data was compared with the image evaluation data using regression analysis in Microsoft Excel.

Image analysis. The computer image vision system was comprised of five principal elements. Camera settings and lighting: Canon-PowerShotG3 digital camera with 4 megapixel, $35 \mathrm{~mm}$ compact/zoom. The camera zoom lens was set $30 \mathrm{~cm}$ above the viewing surface. The area size viewed by the camera was adjusted to the area of the tissue-culture bags $(22.5 \mathrm{~cm}$ horizontally $\times 15 \mathrm{~cm}$ vertically). The bags with stored pear plantlets were placed on the trans-illuminator. Focus and contrast was adjusted to allow a clear outline of the plantlets in the cells. The camera was set with shutter speed at $1 / 500 \mathrm{~s}$, and aperture at $f / 4.0$. The illumination was provided by two fixed lamps (Watt-Miser indoor reflector flood, $120 \mathrm{~W}$ each) each at the right and left sides (Fig. 1). The lights on the same side were $45 \mathrm{~cm}$ apart, and those on opposite sides were $98 \mathrm{~cm}$ apart. The bags were set on a white background with back lighting $\left(20 \mu \mathrm{mol} \mathrm{m} \mathrm{s}^{-2}\right)$ to give high contrast for 


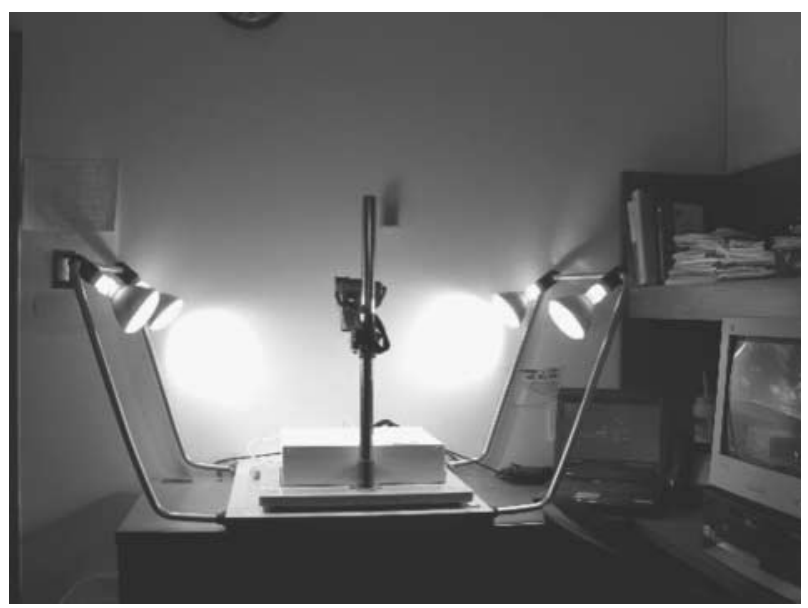

FIG. 1. Components of the digital image system with uniform illumination for in vitro plantlet sample image production.

the plantlets inside each cell. The viewing area was screened to exclude sunlight and the room lights were turned off. Computer software: Analysis was done using Graphic Workshop (www.mindworkshop.com/alchemy/ gwspro.html), Arc Explorer (www.esri.com/software/arcexplorer/), and ArcMap (www.geo.oregonstate.edu/esri/). The Data Crunching Center (DCC; developed in the Department of Horticulture, Oregon State University) and Microsoft Excel were also used.

Image acquisition and processing. Color images were represented as 24-byte images with red, blue, and green bands. Images were cropped and scaled with Graphic Workshop software. Each plant image was isolated from the background and stored as a tag image format file (TIFF) of $c$. $1000 \times 500$ pixels. A pixel represented $20-200 \mathrm{~mm}$. Images were transferred to ArcMap and a polygon was created around each node sampled. Originally, the first and second nodes of each plantlet were represented by $10-15$ pixels each. Later sampling followed those original nodes for the remainder of the study. Sampling areas were held at the same place on each node for each plantlet throughout the experiment. Pixels within the sample shape files were retrieved with DCC software and converted into a database. The mean values for blue, green, and red in each image were calculated using Microsoft Excel. The RGB values were converted to Hue, Intensity and Saturation (HIS) and MNDVI $(\mathrm{R}-\mathrm{G} / \mathrm{R}+\mathrm{G})$ for additional analysis.

Statistical analysis. Five plantlets of each cultivar were analyzed with sampling points on the two upper nodes that were followed through the experiment. Each polygon had a similar number of pixels. Pixel values of the MNDVI, green-to-red ratio (G/R), and HSI were analyzed. Mean rating (MR) values and standard deviations for each cultivar were determined. The image data were compared with visual data using regression analysis.

\section{Results}

Visual analysis. The health of each genotype, as indicated by the visual rating scores of all four genotypes, declined at different rates over the 15-mo. monitoring period (Fig. 2). 'Belle Lucrative' and 'Louise Bonne de Jersey' declined gradually, remaining at mean ratings (MR) $>3$ at 9 mo. 'Luscious' and 'Bartlett-Swiss' declined more rapidly and were rated MR $<2$ at 9 mo. The first significant declines in visual ratings for 'Louise Bonne de Jersey' and 'Belle Lucrative' were observed at 8 mo. At 15 mo., 'Belle Lucrative' had declined to a MR of 2, but
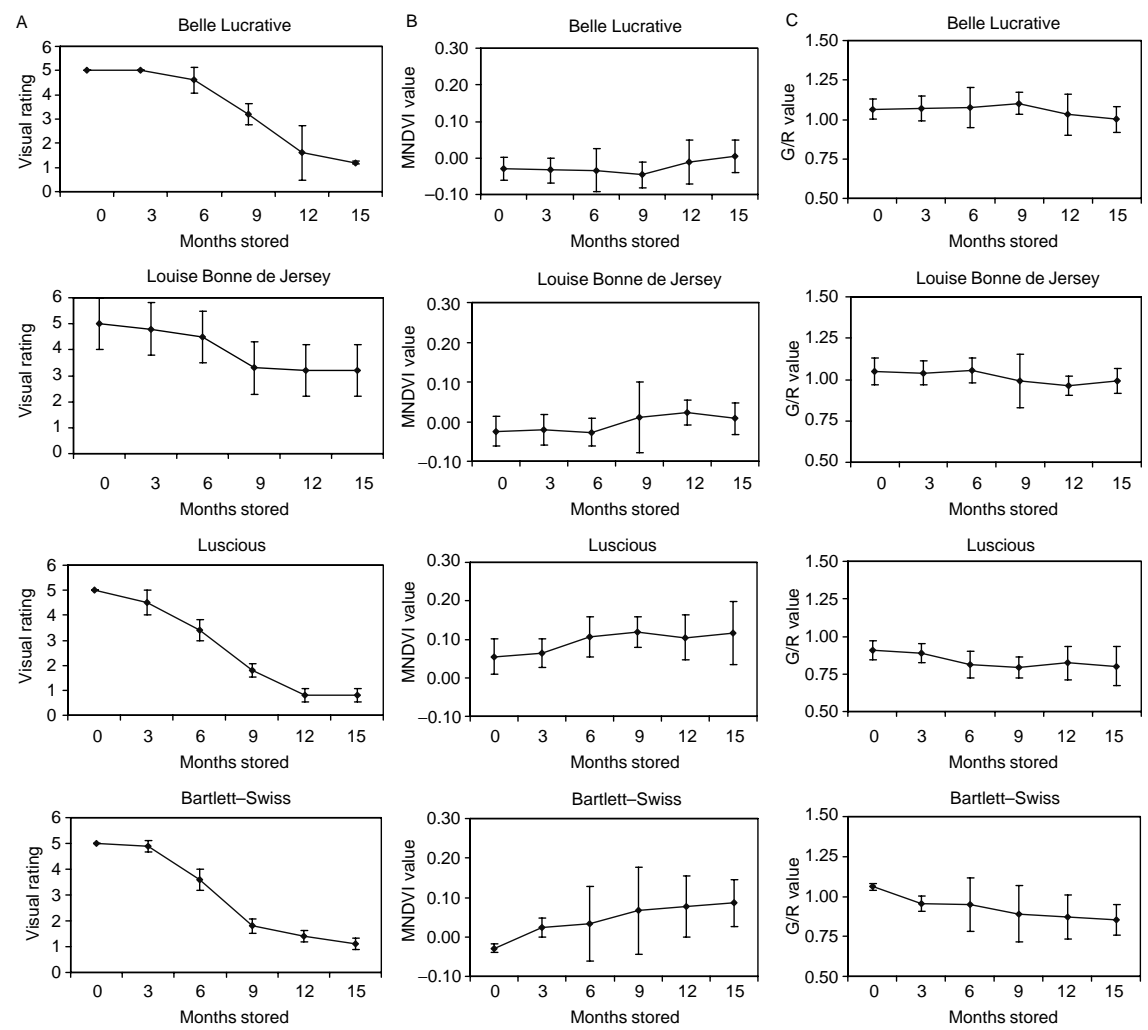

FIG. 2. Mean visual and image analysis ratings of four pear (Pyrus communis) genotypes stored at $4{ }^{\circ} \mathrm{C}$. Ratings were based on mean visual evaluation $(A)$ of 5 plantlets in one storage bag observed over 15 mo. or mean MNDVI values $(B)$ and green-to-red ratio $(C)$ from digital analysis of node 2 of the same plantlets. 
'Louise Bonne de Jersey' ratings remained high ( $M R \geq 3)$. 'Luscious' and 'Bartlett-Swiss' started to decline at 5 mo. $(M R=4)$, and significant declines in MR $<1$ were observed by 12 or 15 mo.

Image analysis. There were only occasional significant differences observed over time in values for RGB and only for some genotypes for hue, intensity, and saturation (data not shown). Significant differences in MNDVI and G/R values over time were observed in some of the genotypes at both nodes throughout the rating period (data not shown), but differences observed at node 2 were more consistently significant (Fig. 2). In general, the MNDVI values increased as plant condition ratings declined, while $G / R$ values decreased over time. Color ratios of 'Bartlett-Swiss' were significantly different between the initial MNDVI and G/R values and the 9- and 15-mo. values (Fig. 2).

Comparison of visual rating and color ratio values. Node 2 was used for comparisons with the visual ratings. Node 2 MNDVI and G/R ratings correlated well with visual ratings for all cultivars (Table 1, Fig. 3). There were no correlations for individual red, blue, or green values but the ratios (MNDVI and G/R) were significant (Table 1). 'Luscious' and 'Louise Bonne de Jersey' showed positive correlations for hue. Saturation and intensity did not correlate with visual ratings for any of the cultivars (Table 1).

\section{Discussion}

Visual analysis. The four P. communis cultivars varied in culture appearance and subculturing time but none declined to $<2$, the selected point for repropagation, until 9 mo. (Fig. 2). The MR remained $\geq 3$ for 6 mo. or longer for all cultivars. The quickest declining genotypes showed significant differences at the early stages of the evaluation period $(5 \mathrm{mo}$.), while the remaining genotypes retained high ratings for 9-10 mo. Most studies show that fixed evaluation and subculturing intervals are effective for genotypes within a single genus (Wanas et al., 1986; Reed, 1991, 1992; Sarkar and Naik, 1998). This study indicates that care should be taken when determining the minimum evaluation period. The four cultivars showed a number of significantly different rating points during the 15mo. storage period. Significant declines occurred in as few as 2 mo. for some genotypes, while the longest period between declines was 7 mo. (individual month's data not shown). This variation in time of decline is supported by other studies, which confirm the use of various evaluation or subculturing intervals (IPGRI/CIAT, 1994; Ashmore, 1997; Dussert et al., 1997). The data obtained in visual rating systems are subjective and therefore ratings vary among evaluators, especially when the plantlets begin to decline. Each cultivar and each individual plantlet in the visual evaluation declined at a different rate.

Digital analysis. Results obtained using digital photography and image analysis software showed that information could be acquired using digital image analysis, with results similar to that of visual analysis. Some consistent color changes noted by image analysis reflected changes in the health of the in vitro-stored pears (Fig. 2). Color change is one of the most observable characteristics relating to microenvironment change in the tissueculture storage system (Smith, 1995) and is an important parameter for measuring the quality of biological products (Shearer and Payne, 1990; Schrevens and Raeymaeckers, 1992). The health of plants or ripening of fruits often can be evaluated by the status of chlorophyll, as seen when tomatoes ripen and the fruit chlorophyll degrades (Choi et al., 1995). The loss or gain of greenness in tissue-culture plants may not reflect large measurable changes in viability, but it can be used as a visible color measurement for tissue deterioration.

Some image analysis studies evaluated shoot growth, root initiation and the development of woody and non-woody plant tissue cultures, but no image analyses have been conducted for nodes (Smith et al., 1989; Smith, 1995). We evaluated the first and second nodes of the stored plants by image analysis to determine if they would reflect the condition of the whole plant, or if one would be more indicative of change than the other. It was anticipated that the average of the nodes would indicate declines comparable to the visual rating, but that was not the case. The results of this study indicated that significant differences in MNDVI and G/R values were more often observed in the second node than the first node or from averaging the values for the two nodes (data not shown).

In this study, individual RGB colors did not signal decline in the stored plantlets, but the color ratios of MNDVI and G/R did. This confirms that color ratios are more reliable than single color values (Choi et al., 1995; Tao et al., 1995; Adamsen et al., 1999). In our study, MNDVI values increased during storage, indicating that as the plantlets browned during storage, the green pixel values decreased more than the red. The pear plantlet MNDVI values increased over the storage period, while visual evaluation ratings and G/R ratios decreased (Fig. 2).

Image evaluation allows acquisition of large amounts of data and images can be stored for further research if needed. The data

TABLE 1

SUMMARY OF $r$ VALUES FROM NODE 2 FOR MEAN DIGITAL RATINGS VERSUS MEAN VISUAL RATINGS FOR ALL CULTIVARS EVALUATED AT 0, $3,6,9,12$, AND 15-MO. TIME PERIODS

\begin{tabular}{|c|c|c|c|c|}
\hline \multirow[b]{2}{*}{ Color Value } & \multicolumn{4}{|c|}{ Cultivars } \\
\hline & Belle Lucrative & L. B. de Jersey & Luscious & Bartlett-Swiss \\
\hline Green/Red & 0.704 & $0.934 * *$ & $0.844 * *$ & $0.904 * *$ \\
\hline Intensity & -0.422 & -0.637 & 0.639 & 0.529 \\
\hline Hue & -0.247 & $0.878^{*}$ & $0.815^{*}$ & 0.694 \\
\hline Saturation & -0.317 & -0.258 & -0.302 & -0.597 \\
\hline
\end{tabular}

Significant at $* P<0.10, * * P<0.05$. 

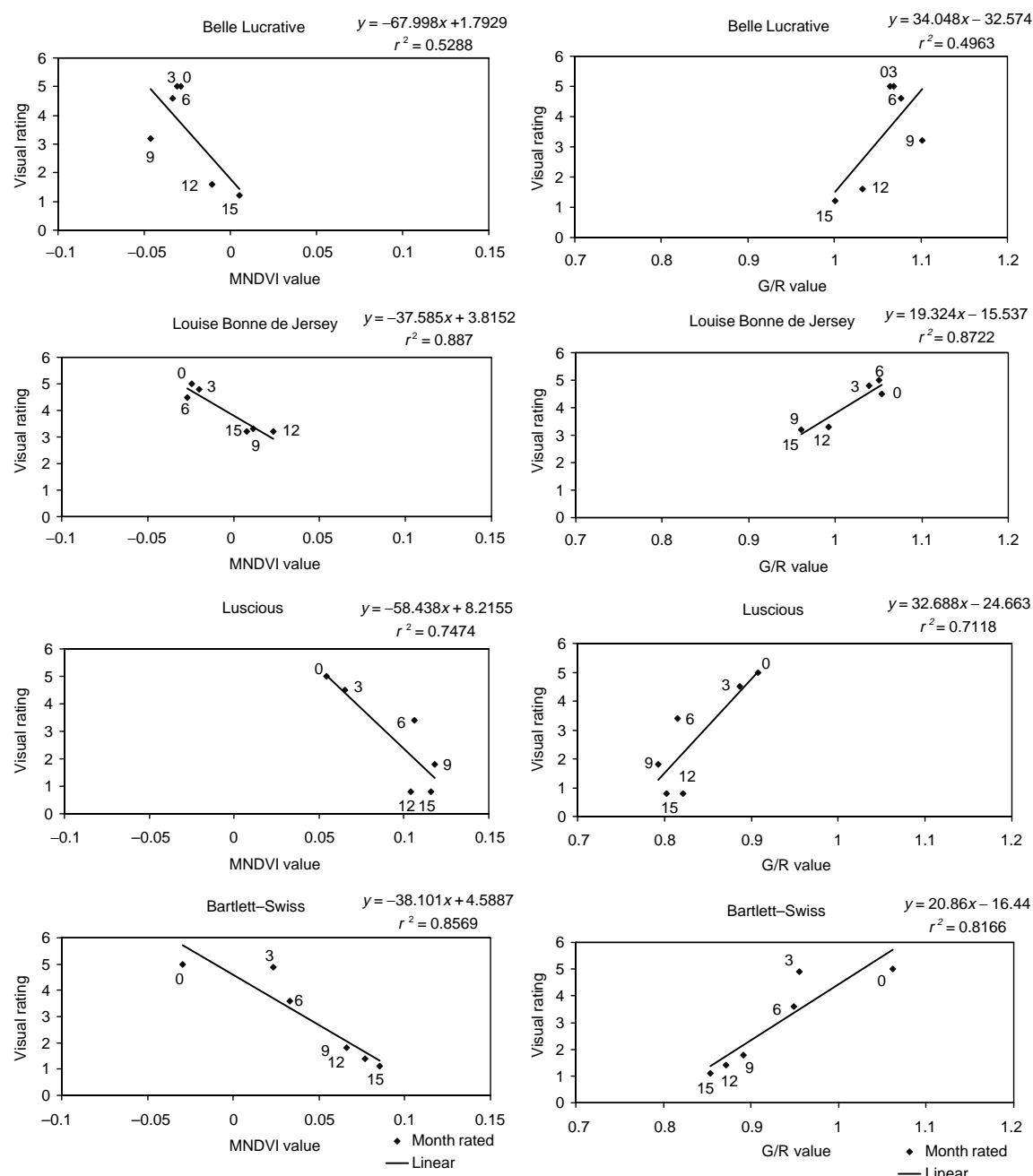

FIG. 3. Regression analysis of node 2 mean MNDVI and G/R values versus mean visual rating for four pear cultivars. after $0,3,6,9$, 12 , and $15 \mathrm{mo}$. of storage at $4^{\circ} \mathrm{C}$. Numbers on data points indicate the month sampled.

obtained through image analysis permitted us to compare color values at the plant nodes with viability measurements. Some difficulties remain in using an image analysis system to evaluate in vitro cultures. Image processing was more time consuming than visual rating and there were many opportunities for error. The surface of the semi-permeable bags used to store the pear plantlets was uneven and produced non-uniform images. The resulting images were variable and more difficult to interpret. Better results might be obtained with a more uniform surface. Slight position changes of plantlets in the storage bags make it difficult to photograph a specific sample location for image analysis. These factors likely explain why image analysis values were more variable than those for visual analysis. More study is needed, however, since the application of automated image analysis currently in development for food grading and processing would allow improved sampling and result in less variability in the color ratio values.

Comparison of visual ratings and color ratio values. The trends of MNDVI and G/R values from image analysis were similar to those observed in the visual rating system. Values for the node 2 mean $r^{2}$ for the G/R and MNDVI color ratios compared to the mean visual rating values were significant for all cultivars (Fig. 3). These results are similar to those used for turfgrass color quantified with image analysis (Karcher and Richardson, 2003). We found more variability in individual values with the image analysis than with visual analysis, probably due to several technical difficulties (Fig. 2). Better-quality photography and an increased number of subsamples for each plant would provide more accurate readings and improved evaluation. The similarities in trends for both systems show that image analysis could be used to automate the process.

\section{Conclusions}

This research demonstrated that image analysis is a feasible approach to evaluate the health condition of in vitro-stored tissuecultured plantlets and has potential as an automated evaluation system. In addition, it may be useful for further understanding physiological changes that occur during cold storage of in vitro plantlets. Changes in the G/R and MNDVI values during the storage period indicated significant differences as plantlet health declined and was noted by the visual evaluation. Changes in MNDVI and $\mathrm{G} / \mathrm{R}$ values were positively correlated with the deterioration of in vitro-stored plants. Further evaluation of more diverse plants 
and improvements in the image processing system are necessary to effectively apply image analysis for routine in vitro plant evaluation. The application of newly developed commercial image analysis systems to this problem would likely improve this evaluation system.

\section{ACKNowledgments}

Funding for this study was provided by USDA-ARS CRIS 5358-21000033-00D. Mention of a trademark, proprietary product, or vendor does not constitute a guarantee or warranty of the product by the USDA and does not imply its approval to the exclusion of other products or vendors that may also be suitable.

\section{ReFERENCES}

Adamsen, F.; Pinter, P.; Barnes, E.; LaMorte, R.; Wall, G.; Leavitt, S.; Kimball, B. Measuring wheat senescence with a digital camera. Crop Sci. 39:719-724; 1999.

Alchanatis, V.; Pelege, K.; Ziv, M. Classification of tissue culture segments by colour machine vision. Agric. Eng. Res. 55:299-311; 1993

Ashmore, S. E., ed. Status report on the development and application of in vitro techniques for the conservation and use of plant genetic resources. Rome: International Plant Genetic Resources Institute; 1997:67.

Cheng, T. Y. Micropropagation of clonal fruit tree rootstocks. Compact Fruit Tree 12:127-137; 1979

Choi, K.; Lee, G.; Han, Y. J.; Bunn, J. M. Tomato maturity evaluation using color image analysis. Am. Soc. Agric. Eng. 38:171-176; 1995.

Cliff, M.; Sanford, K.; Wismer, W.; Hampson, C. Use of digital images for evaluation of factors responsible for visual preference of apples by consumers. HortScience 37:1127-1131; 2002.

Dussert, S.; Chabrillange, N.; Anthony, F.; Engelmann, F.; Recalt, C.; Hamon, S. Variability in storage response within a coffee (Coffea spp.) core collection under slow growth conditions. Plant Cell Rep. $16: 344-348 ; 1997$

Engelmann, F. In vitro conservation of horticultural species. Acta Hort. 298:327-332; 1991.

Gunasekaran, S.; Ding, K. Using computer vision for food quality evaluation. Food Technol. 48:151-154; 1994.

IPGRI/CIAT, ed. Establishment and operation of a pilot in vitro active genebank. Report of a CIAT-IBPGR collaborative project using cassava (Manihot esculenta Crantz) as a model. Rome: International Plant Genetic Resources Institute and International Center for Tropical Agriculture; 1994:59.

Karcher, D. E.; Richardson, M. D. Quantifying turfgrass color using digital image. Crop Sci. 43:943-951; 2003.

Miller, B. K.; Delwiche, M. J. A color vision system for peach grading. Am. Soc. Agric. Eng. 32:1484-1490; 1989.
Neuman, M. R.; Sapirstein, H. D.; Shwedyk, E.; Bushuk, W. Wheat grain color analysis by digital image processing I. Methodology. Cereal Sci. 10:175-182; 1989.

Paulsen, M. R.; McClure, W. F. Illumination for computer vision systems. Am. Soc. Agric. Eng. 29:1398-1404; 1986.

Reed, B. M. Application of gas-permeable bags for in vitro cold storage of strawberry germplasm. Plant Cell Rep. 10:431-434; 1991.

Reed, B. M. Cold storage of strawberries in vitro: a comparison of three storage systems. Fruit Var. J. 46:98-102; 1992.

Reed, B. M. Responses to ABA and cold acclimation are genotype dependent for cryopreserved blackberry and raspberry meristems. Cryobiology 30:179-184; 1993.

Reed, B. M. In vitro storage conditions for mint germplasm. HortScience 34:350-352; 1999 .

Reed, B. Photoperiod improves long-term survival of in vitro-stored strawberry plantlets. HortScience 37:811-814; 2002.

Reed, B.M.; Chang, Y. Medium- and long-term storage of in vitro cultures of temperate fruit and nut crops. In: Razdan, M. K.; Cocking, E. C., eds. Conservation of plant genetic resources in vitro. Enfield, $\mathrm{NH}$ : Science Publishers Inc.; 1997:67-105.

Reed, B. M.; DeNoma, J.; Luo, J.; Chang, Y.; Towill, L. Cryopreservation and long-term storage of pear germplasm. In Vitro Cell. Dev. Biol. Plant $34: 256-260 ; 1998$

Reed, B. M.; Engelmann, F.; Dulloo, E.; Engels, J., eds. Technical guidelines for the management of field and in vitro germplasm collections. Rome: IPGRI/FAO/SGRP: 2005:1-95.

Sacks, E. J.; Shaw, D. V. Optimum allocation of objective color measurements for evaluating fresh strawberries. J. Am. Soc. Hort. Sci. 119:330-334; 1994

Sarkar, D.; Naik, P. S. Factors affecting minimal growth conservation of potato microplants in vitro. Euphytica 102:275-280; 1998.

Schrevens, E.; Raeymaeckers, L. Colour characterization of golden delicious apples using digital image. Acta Hort. 304:159-161; 1992.

Shearer, S. A.; Payne, F. A. Color and defect sorting of bell peppers using machine vision. Am. Soc. Agric. Eng. 33:2045-2050; 1990.

Smith, M.A. Image analysis for plant cell culture and micropropagation In: Christie, A. J.; Kozai, T.; Smith, M. A., eds. Automation and environmental control in plant tissue culture. Dordrecht, The Netherlands: Kluwer Academic Publishers; 1995:145-163.

Smith, M. A. L.; Spomer, L. A.; Meyer, M. J.; McClelland, M. T. Noninvasive image analysis evaluation of growth during plant micropropagation. Plant Cell Tiss. Organ Cult. 19:91-102; 1989.

Tao, Y.; Heinemann, P. H.; Varghese, Z.; Morrow, C. T.; Sommerlii, H. J. Machine vision for color inspection of potatoes and apples. Am. Soc. Agric. Eng. 38:1555-1561; 1995.

Van de Houwe, I. INIBAP Germplasm Transit Centre: managing the in vitro medium term genebank for Musa spp. In: Engelmann, F., ed. Management of field and in vitro germplasm collections. Rome: International Plant Genetic Resources Institute; 1999:127-131.

Wanas, W. H.; Callow, J. A.; Withers, L. A. Growth limitations for the conservation of pear genotypes. In: Withers, L. A.; Alderson, P. G., eds. Plant tissue culture and its agricultural applications. London: Butterworths; 1986:285-290. 